\title{
Misinformation: Toward Creating a Prevention Framework
}

\author{
Alex Koohang \\ University of Wisconsin, Milwaukee, USA
}

koohang@uwm.edu

\author{
Edward Weiss \\ National-Louis University, Chicago, USA
}

eweiss@nl.edu

\begin{abstract}
Misinformation is unintentional dissemination of misleading information. Misinformation can negatively influence decision-making and productivity within organizations. Therefore, it is essential for organizations to follow a set of principles to prevent misinformation. The purpose of this paper is to create a framework for preventing misinformation. This paper attempts to 1) clarify differences between misinformation and disinformation; 2) identify the person responsible for information and information dissemination; and 3) present a proposed framework for misinformation prevention that includes three phases: information identification, information analysis, and information organization.
\end{abstract}

Keywords: Misinformation, Information unbiased, Disinformation, Information biased, Information Architecture, Decision-making, Misinformation Prevention Framework, Information Architect

\section{Introduction}

The Internet is an attractive place for almost anyone who wishes to put out information. The freedom the Internet affords, unfortunately, contributes to deficiency in information quality control (Piper, 2000, Mintz, 2002). The information published on the Internet, therefore, can easily become misinformation and travel through a multitude of networks readily available to be used. Coffee (2001) states that people are being increasingly misinformed through the Internet. He further argues that people receive information that is inaccurate or misleading. This misinformation can significantly contribute to counter productivity.

Because misinformation can negatively influence decision-making and productivity, it is essential for organizations to follow a set of guiding principles to prevent misinformation. The purpose of this paper is to offer a framework for misinformation prevention within organizations. This paper attempts to discuss differences between misinformation and disinformation; identify the person responsible for information and information dissemination; and systematically present the misinformation prevention framework.

Today, there are many complicated types of information, misinformation, and disinformation. Misinformation is much more than just a bug and disinformation is much more than a virus. Misinformation is unintentional dissemination of misleading information. However, disinformation is the intentional dissemination of misleading and wrong information.

Material published as part of these proceedings, either on-line or in print, is copyrighted by Informing Science. Permission to make digital or paper copy of part or all of these works for personal or classroom use is granted without fee provided that the copies are not made or distributed for profit or commercial advantage AND that copies 1) bear this notice in full and 2) give the full citation on the first page. It is permissible to abstract these works so long as credit is given. To copy in all other cases or to republish or to post on a server or to redistribute to lists requires specific permission from the publisher at Publisher@Informingscience.org
Although the human capacity for rationality includes the ability to discern among highly complex and vast quantities of information it receives, technology and the geometric intensification in information provided by that technology give the potential for obfuscating that information. The result is that information itself as well as its processing and managing have become much more 
difficult, often with insurmountable problems leading to more opportunities for misinformation.

\section{Information, Misinformation, and Disinformation}

The meanings of information have been more than arithmetically, if not geometrically, increased by the pervasiveness of the Internet and the plethora of information that it provides. Information has come to take on a number of connotations.

Information is defined by Stair and Reynolds (2001, p. 4) as a "collection of facts organized in such a way that they have additional value beyond the value of facts themselves". They add that if the information is to be considered good and valuable, it must be accurate, complete, economical, flexible, reliable, relevant, verifiable, and secure. Looking closely at this the following questions can be asked: Is it ne cessary for the facts to be true? Can there be false facts? How does one conceive of a false fact? This brings to mind the problem of Socrates. How does one mentally visualize a circle that isn't circular?

The problem is further complicated when misinformation is considered as a subset of information. In the first assumption we put forward, we will assume the counter-intuitive position that facts need not be true, but will be assumed to be true, unless otherwise stated. In other words, for purposes of furthering definitional litany, "elephants fly" will be a false fact. However, in common usage, it is false and will not be considered a fact at all.

Misinformation, the unintentional dissemination of misleading information, is the focus of this paper. However, the distinction between misinformation and disinformation is necessary because misinformation need not be false. Something can be true and still be misinformation. For example, one sees something out of the corner of his/her eye and it is moving quickly right at the person. The person's amygdala kicks in and the person instinctively ducks. When the person is not hit with anything, or does not even experience a near miss, and upon ultimate recovery, the person sees that $\mathrm{s} / \mathrm{he}$ has mistaken a reflection of an object for the object itself. The reflection was a true one and thus a fact; as a reflection, it was even accurate, complete, reliable, relevant and verifiable. However, it is still what we would consider misinformation, as opposed to information.

Disinformation is the intentional dissemination of misleading information. It is presented in such a way as to purposely mislead. For example, one sees something out of the corner of his/her eye and it is mo ving quickly right at the person. The person instinctively ducks. When the person is not hit with anything, or does not even experience a near miss, and upon ultimate recovery, the person sees that s/he has mistaken a reflection of an object for the object itself. The reflection was a true one and thus a fact; as a reflection, it was even accurate, complete, reliable, relevant and verifiable. However, it was a trick. The reflection was purposefully caused to mislead. Not everyone would fall for the practical joke, but some would. Anyone who did respond was a victim of disinformation.

The facts in each scenario were both identical and true, yet presented as examples of misinformation information unbiased and disinformation - information biased. There are other possibilities as well. For example, a person operating under requirements of full disclosure, over-disclose; in other words, provide many more true facts than necessary in the hopes that the superfluous true facts will hide the relevant true facts. This is another obvious example of disinformation, but true disinformation, nonetheless.

If some of those superfluous true facts were unintentionally included with the relevant true facts, it would be an example of misinformation as opposed to disinformation, however; true misinformation.

Often the above distinctions may appear to be of the "How many angels can dance on the head of a pin?" variety. However, these distinctions are not mere subtleties, in spite of the possible disdain in which many might hold them. In fact, the opposite is the case - they are not at all as complete or as clear as those who understand them and would ordinarily insist that they be. 
This is but one of the problems confronted when using an interdisciplinary and cross-functional approach. The subtleties of one discipline frequently become the ridicule of another. In any case, these distinctions are required for those responsible for information and its dissemination.

At the very least, there is the epistemological problem of correlation, as opposed to cause and effect. Correlations, while far from false facts, are not quite true facts either. Someone has to decide under what circumstances and how close the correlation need be.

\section{Application}

Information Architecture (IA) is a new and emerging discipline that is gaining momentum among information communities. IA is the investigation, analysis, organization, and implementation of information. Top-down and bottom-up are the main two approaches in developing IA. The Bottom-down approach focuses on developing the IA with consideration of the content and the tools that are used to support the content. The top-down approach focuses on developing the IA with consideration of the context of the content where users' needs and specifications are the center of the attention. These approaches are often developed concurrently (Cortez, 2002). Rosenfeld \& Morville (1998) linked the term with design and development of large, information-rich web sites. In 2000, the American Society for Information Science and Technology (ASIS\&T) made the IA term official (Dillon, 2002).

The person who is responsible for creating IA is Information Architect. Wurman (1996) stated that the information architect is the person who is responsible for organizing the patterns inherent in data, making the complex clear. S/he creates the structure and maps the information. S/he addresses the needs for clarity, human understanding, and the science of the organization of information.

Therefore, the authors of this paper believe that the information architect may be the rightful responsible person for information within any organization. The information architect must possess adequate knowledge about distinguishing between information and misinformation. The information architect must also rely on interdisciplinary and cross-functional principles within the organization. S/he will need the assistance of actuaries, economists, engineers, ethicists, etc. in order to prevent misinformation.

\section{The Misinformation Prevention Framework}

Information is a valuable commodity. True information can contribute to sound decision-making. Disseminating true information becomes a challenge for organizations and people who are responsible for it. The proposed Framework in this study can be used as a guiding principle for information architect in order to prevent dissemination of misinformation. This framework consists of three phases. They are: 1) Information Identification, 2) Information Analysis, and 3) Information Organization (See Figure 1). This framework assumes that the information architect will have the sole responsibility for all phases of misinformation prevention framework, making every effort to minimize or eliminate misinformation before disseminating information for decision- making.

The misinformation prevention framework relies intensely on interdisciplinary and cross-functional principles within the organization. Understanding information ecology is vital in the process of misinformation prevention. Nardi and O'Day $(1999$, p. 1) defined information ecology as "a system of people, practices, values, and technologies in a particular local environment." It is likely that people have particular information about their own local ecologies that is not accessib le to anyone beyond their domain. In an environment of lively information ecology, this information must be shared. Within this framework, information should not be viewed as asymmetric. Information must be shared even if it is not to the advantage of the person(s) possessing the information. People possessing information should not act in their own self-interest. 
Upon completion of each phase, the information architect will seek assistance from designated persons in interdisciplinary and cross-functio nal disciplines within the organization. This is a vital checkpoint to make sure that all steps are followed properly in each phase. If inspection passes, then information architect must proceed to the next phase. If inspection does not pass, then further examination is required. The three phases in the misinformation prevention framework are described below.

\section{Phase I: Information Identification}

This phase deals with identification of necessary information. Information must be defined and described. The nature of information must be recognized and acknowledged. This phase must define what the information is intended to accomplish.

One of the major tasks in this phase is to assess information needs. Various techniques for determining information needs could include direct observation, interviews, and surveys. While assessing information needs through these techniques, careful attention must be given to information relevancy and its relation to information needs.

The information identification specifically deals with the following:

- Defining and describing information.

- Identifying the nature of information.

- Understanding and defining what the information is intended to accomplish.

- Understanding information needs.

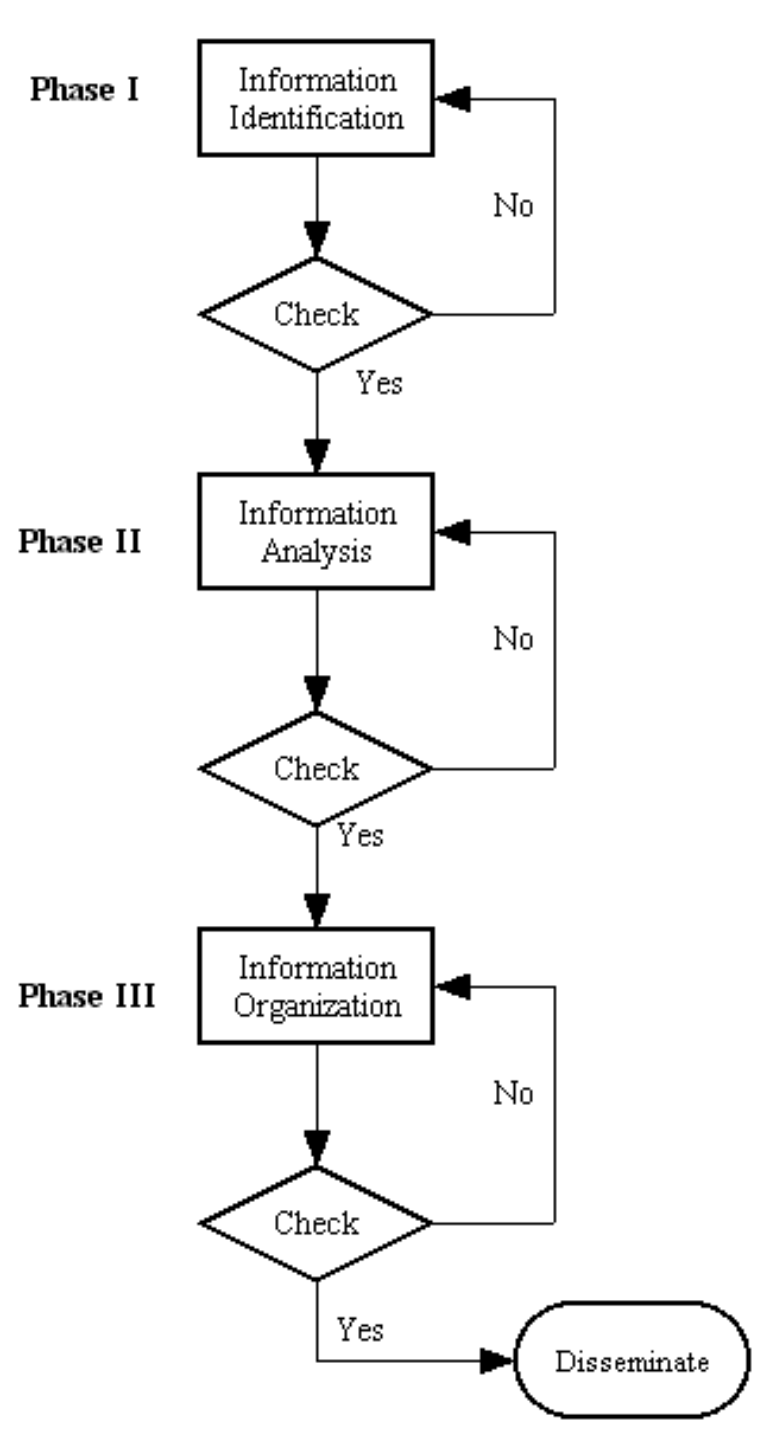

Figure 1: Misinformation Prevention Framework

Before proceeding to the next phase, the informa-

tion architect must seek assistance from designated persons in interdisciplinary and cross-functional disciplines within the organization to ensure that all steps in phase one are followed properly.

Alexander \& Tate (2001) delineated five different classifications for information sources. They are: advocacy (sponsored by organizations attempting to vend ideas), business/marketing (backed by commercial enterprises attempting to promote or sell products), news (attempting to provide news/reports), informational (sponsored by government and/or educational institutions attempting to present factual information), and personal (attempting to provide personal information).

Recognizing and distinguishing the sources of information in the information identification phase is a vital task. This will help dealing with biased information in the information analysis phase. 


\section{Phase II: Information Analysis}

Information analysis is the most crucial and detailed phase. The information analysis should include a blueprint that outlines the total functionality of the information, the source of the information, the information architecture, and the content. The blueprint should act as a groundwork in which the information for use and decision-making can be determined.

The analysis phase goes beyond merely understanding the information. It determines the value of information that eventually will be used to make sound decisions. This phase will determine accuracy, completeness, and relevancy of information. It must identify internal and external controls that guarantee the information will be reliable. It verifies and validates the information by searching the resources used to author and/or access the information. It checks to see if the information is certified and legal. In general, the analysis phase deals with the relationship between information, the context of the information, and the users who access the information.

The scope of the information refers to the usefulness, uniqueness, and accuracy of information. Information should not be deriv ative, repetitious, or doubtful. The information must fulfill the purpose. It should be factual. It should not be biased. Facts and opinion must be separated from collected information. Facts are events that actually occurred. They are precise, verifiable, specific, and true. Opinions are thoughts, views, judgments, and feelings that are not backed up by facts. Inconsistencies among information that is accesses from different sources must be confirmed. The frequency of the information update must also be confirmed. The sponsor(s) of the information must be verified. In most cases, the motives and intentions of the sponsoring organization must be taken into consideration. This may help clarify and make intelligent analysis about possible bias. The information must be authentic and come from credible sources. This will help possible information bias and misinformation. Reliable and reputable sources that are likely to be most useful for fact gathering should be given careful atte ntion.

Verification of the person or persons' credentials and affiliation that authored the information is vital task. The author of the information should have expertise in the field. In some cases the author of the information can be contacted for clarification.

The information analysis phase specifically deals with the follo wing:

- Identifying internal and external controls that guarantee the information will be reliable.

- Verifying and validating of information.

- Confirming certified information and information legality.

- Including a blueprint that outlines the total functionality of the information, the source of the information, the information architecture, and the content.

- Recognizing of the scope of information.

- Separating the facts and opinion from each other.

- Verifying sponsors of information.

- Examining information inconsistencies.

- Verifying the information author's credentials and affiliation.

Table 1 outlines a short list of resources that are useful for information analysis. These sites are among many valuable sources that offer information verification, reliability, legality, accuracy, inconsistency, etc. Before proceeding to the next phase, the information architect must seek assistance from designated persons in interdisciplinary and cross-functional disciplines within the organization to ensure all the steps in phase two are followed properly. 


\section{Phase III: Information Organization}

Once the information is analyzed it must be organized for dissemination. This phase must deal with customization information for a specific environment. Information should be organized so it can be found and understood easily. The information must be presented clearly and logically in an orga nized format that is useful to the target audience. The information must be clearly and appropriately labeled. Organizing information can be achieved by creating an information map. The information should not be cluttered and the navigational elements should be clearly identified. The information must be readable and to the point. The key points must be highlighted. It must be presented with visual clarity that includes headlines, bolded words, tables, and visual structure. The organization of information deals specifically with the following:

- Customization for a specific environment.

- Easily finding and understanding information.

- Appropriate and clear labeling.

- Clear and logical formatting.

- Including an information map.

- Identification of clear navigational elements.

- Determining key points.

- Determining and including visual clarity.

Determining the amount of information to be disseminated is a vital task. Only disseminate information that is necessary for decision-making. Before disseminating information, the information architect must seek assistance from designated persons in interdisciplinary and crossfunctional disciplines within the organization to ensure that all steps in phase three are followed properly. Finally, evaluation of the information is an on-going task. The information must continuously be evaluated and checked.

- Basic information about a Web site can be found at http://www.arin.net/whois/, http://www.nic.uk/, http://www.internic.net/whois.html, or http://www.samspade.org/.

○ Librarians' Index to the Internet at http://lii.org is a trusted place to search for information.

- Argus Clearinghouse for a web site review at http://www.clearinghouse.net/.

- Biography resources are available at http://www.ala.org/acrl/resjan02.html. This site finds information on the famous, infamous, and obscure.

- Internet Scout Report at http://scout.cs.wisc.edu is a weekly publication that offers a collection of new and newly discovered online resources that may be useful to researchers, educators, and those involved in information analysis.

- Scholarly Internet resource collections are available at http://infomine.ucr.edu/.

- A list of online directories and bar association web sites is available at http://www.llrx.com/columns/reference32.htm This list can be used to find information about legal professionals who own sites.

- For fraud and consumer protection use http://www.sec.gov/investor/pubs/cyberfraud.htm, http://www.fraud.org/internet/intset.htm, and/or http://www.ftc.gov/ftc/consumer.htm.

- LexisNexis at http://www.lexisnexis.comand Westlaw at http://web2.westlaw.com/signon/default.wl have comprehensive news libraries for conducting search on web sites, their owners and authors. Information can be accesses from these sites by paid subscription.

Table 1: A Short List of Resources for Information Analysis 


\section{Conclusion}

Misinformation is unintentional dissemination of misleading information. Misinformation can negatively influence decision-making. Therefore, every measure must be taken to ensure that information disseminated is true information. This paper presented a framework for the prevention of misinformation. The framework consists of three phases - information identification, information analysis, and information organization. The framework stresses the need for a person such as an information architect who is solely responsible for information and its dissemination. In each phase useful guidelines are given to the person responsible for information to ensure that information is disseminated without error. Each phase within the framework accentuates the need for the information architect to seek assistance from designated persons in interdisciplinary and cross-functional disciplines within the organization to ensure that the information will be accurate, valid, legal, etc.

The proposed framework is an effort toward preventing misinformation. It ought to be given careful attention when disseminating information for decision-making. Attempts should be made to further delineate and/or modify this framework in future research.

\section{References}

Alexander, J. \& Tate, M. (2001). Evaluating Web Resources. Retrieved February 02, 2003 from http://www2.widener.edu/Wolfgram-Memorial-Library/webevaluation/webeval.htm

Coffee, P. (2002). Getting an answer is one thing, learning is another. eWeek: Ziff Davis Media Inc.

Cortez, E. (2002). Specialization in Information Architecture. Working Document for the ASIS\&T Education Committee. University of Wisconsin, Madison.

Dillon A. (2002). Information Architecture in JASIST: Just Where Did We Come From? Journal of the American Society for Information Science and Technology, 53(10), 821-825.

Mintz, A. (2002). Web of Deception: Misinformation on the Internet. New Jersey: Information Today, Inc.

Nardi B. \& O’Day, V. (1999). Information Ecologies: Using Technology with Heart. MIT Press. Retrieved February 02, 2003 from http://www.firstmonday.dk/issues/issue4_5/nardi_chapter4.html

Piper, P. (2000). Better read that again: Web hoaxes and misinformation. Searcher, 8(8). Retrieved February 02, 2003 from the Word Wide Web http://www.infotoday.com/searcher/sep00/piper.htm

Rosenfeld, L, \& Morville, P. (1998). Information architecture for the World Wide Web. Cambridge: O'Reilly.

Stair, R \& Reynolds, G. (2001). Principles of information systems, 5th ed. Course Technology: Cambridge: MA

Wurman, R.S. (1996). Information architects, ed. Peter Bradford. Graphics Press: Zurich

\section{Biographies}

Alex Koohang is an associate professor and director of undergraduate program in the School of Information Studies at University of Wisconsin - Milwaukee. His current research interest is information architecture, e-learning/distance education, and usability.

Edward Weiss is a professor in the College of Management \& Business at National-Louis University, Chicago, Illinois. His current research interest is information ethics and distance education. 